\title{
Enumerated Treatment Regimens
}

National Cancer Institute

\section{Source}

National Cancer Institute. Enumerated Treatment Regimens. NCI Thesaurus. Code C159873.

Treatment regimens that are enumerated to provide disctinction from each other. 